\title{
36. Süddeutsches AOTrauma-Seminar am Universitätsklinikum Regensburg
}

Christian Pfeifer, Michael Nerlich

Nachdem die AO im Jahre 2018 seit mehr als 60 Jahren zur verbesserten Versorgung von Frakturen und Frakturfolgen beigetragen hat, stand beim diesjährigen Süddeutschen AOTrauma-Seminar vor allem das Thema „Wenn Bewährtes versagt, was dann?“ im Mittelpunkt. Neben zahlreichen namhaften nationalen und internationalen Referenten, die mit Schwerpunktvorträgen Lösungsansätze für Osteosyntheseversagen vorstellten, konnten die Teilnehmer vor allem im Rahmen von Falldiskussionen selbst viele Aspekte rund um die Thematik Salvage-Verfahren aktiv beitragen.

Hüftgelenksnahe, kniegelenksnahe und sprunggelenksnahe Problemfälle konnten eine weite Bandbreite an möglichen Therapiekonzepten aufzeigen, die im Rahmen von Pseudarthrosen, Achs- und Rotationsfehlstellungen sowie periimplantären Frakturen zum Einsatz kommen. Durch die Fallvorstellungen führte die Faculty unter Anleitung der Professores Nerlich, Gebhard, Stöckle, Biberthaler und Südkamp, und es entwickelten sich lebhafte Diskussionen um die gezeigten Fälle.

Ein weiterer Höhepunkt stellte die Live-Demonstration eines dorsalen Zugangs zum Sprunggelenk dar. Dies wurde nach Einführung zum Thema durch Prof. Bartoníček (Prag) demonstriert und die Wichtigkeit der dorsalen Versorgungsmöglichkeiten am Sprunggelenk betont.

Bei der offiziellen ARS-Bewertung schnitten die Diskussionen über insgesamt 13 Fälle und die Live-Zugangs-Demo am menschlichen Präparat exzellent ab. Die 50 Teilnehmer waren von der Veranstaltung insgesamt hellauf begeistert und engagiert bei den Diskussionen dabei. Die Faculty des diesjährigen AOTrauma-Seminars war echt gefordert, die lebhaften Diskussionen um die besagten Fälle zu leiten.

Dass die Falldemonstrationen durch den unfallchirurgischen Nachwuchs der eigenen Klinik so hervorragend präsentiert wurden, hat die wissenschaftlichen Organisatoren sehr beeindruckt.

PD Dr. Christian Pfeifer, Regensburg

Prof. Dr. Michael Nerlich, Regensburg

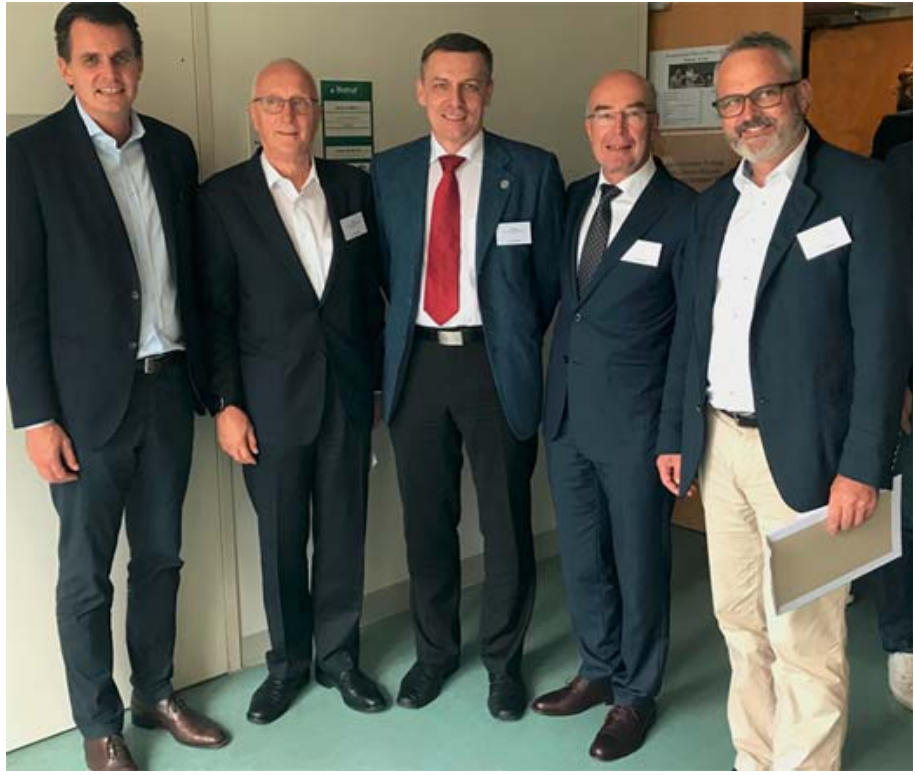

- Abb. 1 Die Faculty Stöckle, Südkamp, Bartonicek und Gebhard mit Gastgeber Nerlich (2. von rechts). Quelle: AO Foundation

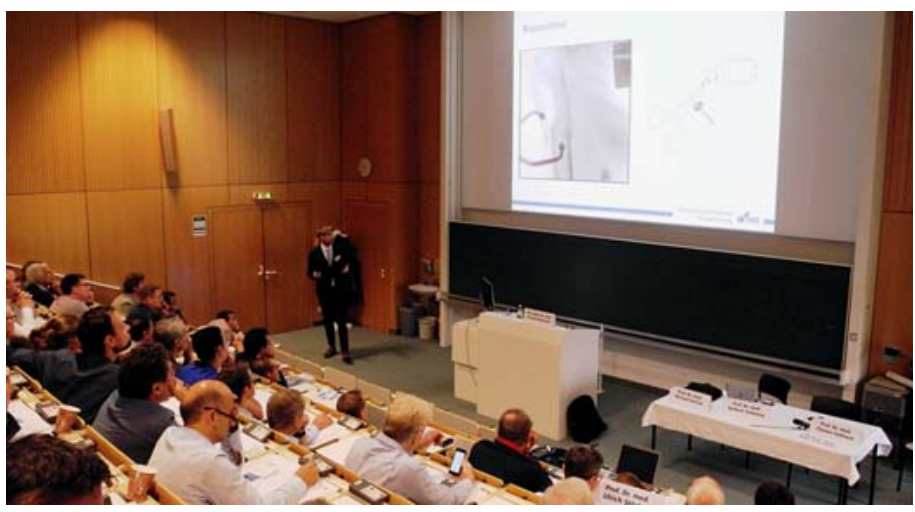

- Abb. 2 Vortrag von Florian Baumann. Quelle: AO Foundation

Bibliografie

DOI https://doi.org/10.1055/a-0749-4631

OP-JOURNAL 2018; 34: 341 @ Georg Thieme Verlag KG Stuttgart · New York ISSN 0178-1715 